\title{
Assessing urban water sustainability in South Africa - not just performance measurement
}

\author{
K Carden* and NP Armitage \\ Department of Civil Engineering, University of Cape Town, Private Bag X3, Rondebosch 7700, South Africa
}

\begin{abstract}
Urban water management - and the impacts that rapid population growth, industrialisation and climate change are having on it - is gaining increasing attention worldwide. In South Africa (SA), cities are under pressure to respond to not only the challenges of water availability and quality, but also to economic transformation and social division. New solutions for improving the sustainability of cities need to be found, including the development of tools to guide decision-makers. Several benchmarking initiatives have been implemented in the SA water sector - mostly in terms of performance measurement of specific water services for regulatory purposes - but none provide an integrated analysis to enable a deeper understanding of sustainability. The research described in this paper was thus focused on using a systems approach to create an understanding of, and measure the potential for, sustainability in a South African urban water context. This has been achieved through the development and evaluation of a composite index, the Sustainability Index for Integrated Urban Water Management (SIUWM). The first step involved compiling a vision of sustainability for the SA water sector, and expanding it into a sustainability framework to help identify suitable indicators for the assessment process, as well as those which link with existing measurement initiatives. Key performance indicator results from the Department of Water Affairs' Regulatory Performance Management System (RPMS) and the Blue Drop / Green Drop schemes were used as partial input to the SIUWM, and scores were computed for the nine member cities of the South African Cities Network (SACN). The SIUWM links the results from the regulatory systems with a broader sustainability assessment process to provide a more detailed analysis which can be used to establish goals and inform strategic processes to leverage support for improved water services. In this way, the connections that link the different aspects of urban water management can be used to generate a greater awareness of the underlying issues by key decision makers and thus guide appropriate action.
\end{abstract}

Keywords: urban water management; sustainability index; performance measurement

\section{INTRODUCTION}

Urban water management issues - and the impacts that rapid population growth, industrialisation and climate change are having on water resources and the environmental capabilities of cities - are gaining increasing attention worldwide. The main challenges in this regard concern: access to services (especially for the urban poor); over-exploitation of water resources; pollution of ground- and surface-water resources; health impacts (from inadequate sanitation facilities and contaminated drinking water supplies); and leakage/wastage of up to $50 \%$ in some urban water distribution systems (UNW-DPAC, 2010). It has been suggested that a new paradigm needs to be applied to solve what has been termed 'a growing water crisis' (UNESCOIHP, 2008), including the development of analytical tools for the assessment of urban water conditions and for the encouragement of integrated urban water management (IUWM) in various settings. An IUWM approach views water supply, drainage and sanitation as components of an integrated physical system (the urban water cycle), whilst recognising that the system resides within an organisational framework as well as in the larger natural landscape (Mitchell, 2006). A key theme of the 2011 Human Development Report (UNDP, 2011) was the need to fully integrate equity concerns into policies at national

This paper was originally presented at the 2012 Water Institute of Southern Africa (WISA) Biennial Conference, Cape Town, 6-10 May 2012.

* To whom all correspondence should be addressed.

I

e-mail: Kirsty.Carden@uct.ac.za and local government level; institutions need to be accountable and inclusive to allow civil society access to information and enable transparent deliberative processes. Coordinated implementation, monitoring, reporting and verification systems are proposed as ways of bringing about long-term accountability to local populations as well as to government partners.

In addition to the challenges of water availability and quality being experienced globally, South African cities are also under pressure to respond to issues of economic transformation and social division. Despite accelerated basic service delivery, many local authorities are battling to keep pace with urbanisation, intensifying competition for scarce resources and raising social tensions. The South African National Water Act (No. 36 of 1998) is seen as one of the most progressive legislative and policy frameworks for water management in the world (Tissington et al., 2008), and is built on the principles of integrated water resources management (IWRM), which emphasises the need for participatory processes at all levels (RSA, 1998). A critical lack of capacity and technical skills has however seriously impacted on national and local authorities' ability to control and manage the water sector. The National Planning Commission of South Africa has recently stated that 'providing high-quality public services is the single most important thing that can be done to overcome the inequalities of apartheid' (RSA, 2011a). Their vision is one of transforming the public service and improving state performance through enhancing institutional capacity by way of a 'polycentric governance' model in which local government will retain responsibility for ensuring adequate service provision in its areas, and regional authorities (assumed to have higher levels of competencies) will provide services in cases where municipalities have 
inadequate technical and financial capabilities (RSA, 2011b). Results-based performance measurement processes at national and local government level can be used to refine and manage these service improvement programmes as well as form the basis of a coordinated sustainability analysis for the water services sector.

The concept of sustainability (as it relates to sustainable water services) was described by the Department of Water Affairs and Forestry (DWAF, now DWA - Department of Water Affairs) as a 'vision of a community's future where the vision is community oriented and focused on long-term goals. It takes into account linkages between the social, economic, institutional and environmental aspects of the community' (DWAF, 2008). The purpose of sustainability assessment is to try to determine whether the current path being trod will be the same path to be trod in the future. It determines the likelihood of being able to proceed in the same manner such that a similar or better quality of life is maintained. This assumes some form of future 'management', which concerns much more than just scenario planning, but is also about developing methodologies that prioritise actions, engage with stakeholders and enable proactive action. The process needs to be well-informed so that implementation strategies have buy-in, are relevant and far-reaching.

In the recent IWA report on 'Global trends and challenges in water science, research and management' (Beck et al., 2012) it was noted that determining progress away from unsustainability and towards 'water-sensitive' cities is currently extremely difficult to evaluate. Water sensitive cities are described as those which make use of adaptive, multifunctional infrastructure and urban design to reinforce water-sensitive behaviours and achieve sustainable urban water conditions (Brown et al., 2008). More effort needs to be directed towards tracking urban water sustainability at both utility and city level, in order to benchmark progress in city policies and to discriminate between leading sustainability practices and those that are lagging behind (Beck et al., 2012). The preparation of a factbased vision for the water sector is a critical first step in making the adoption of a new urban water paradigm possible (Addams et al., 2009). The aims of this research were therefore to use a systems approach to create an understanding of, and measure the potential for, sustainability in a South African urban water context. This has been achieved through the development of a framework for identifying sustainability indicators based on an agreed vision of what is required to meet the challenges of, inter alia, population growth, climate change and decreasing water quality. This paper describes the application of the resultant composite index, the 'Sustainability Index for Integrated Urban Water Management' (SIUWM) to a number of case study cities in South Africa (SA), and highlights some of the crisis areas in urban water management in an attempt to help local authorities establish goals and inform strategic processes to leverage support for improved water services.

\section{Performance measurement in the South African water sector}

Benchmarking and performance assessment in the water supply and sanitation sector is seen as a low-cost and effective tool for improving the performance of water utilities (UNESCO-IHE, 2009). Several benchmarking initiatives have been implemented in the SA water sector in recent years - both at municipal water services level to improve operational business performance (e.g. the National Municipal Benchmarking Initiative, NBI), as well as in terms of performance measurement of water services for regulatory purposes. In this regard, the Department of Water Affairs has implemented a National Water Services Regulation Strategy (DWA, 2010), aimed at addressing the poor performance of municipalities or water services authorities (WSAs) in both the delivery of infrastructure and the provision of services. Three priority programmes have been put in place in order to mitigate key risks to the successful implementation of the strategy:

- A concentrated regulatory effort to address compliance and performance issues in municipalities - the Regulatory Performance Measurement System (RPMS)

- A national drinking water quality regulatory initiative (Blue Drop)

- A national effluent quality regulation initiative (Green Drop)

The RPMS measures performance in each WSA according to critical issues in 11 key performance indicator (KPI) areas and against regulatory standards (or benchmarks) for some of these KPIs. It comprises two distinct aspects: performance measurement and regulatory action. The annual data collection process is streamlined and the system is web-based and accessible to public users, WSAs and Department of Water Affairs (DWA) water sector partners. Drinking water quality and wastewater management are regulated by way of the incentive-based Blue Drop and Green Drop systems, which acknowledge excellence by way of certification for compliant WSAs.

What benchmarking initiatives such as these fail to do, however, based on the fact that they are focused on efficiency and service provision to existing customers, is to take into account service provision to the poor (and the resultant impacts when services are non-existent or dysfunctional), as well as provide an indication of the potential for overall sustainability of the urban water system as a whole. For example, a city's water services may seem to be operating 'efficiently' in terms of the regulatory requirements for drinking water and wastewater treatment, but if a significant proportion of its residents do not have access to services, the urban water system is not sustainable. This is especially relevant in a developing country such as South Africa where a context-specific interpretation of sustainability needs to take into account social and institutional issues such as poverty alleviation, strengthening democracy, skills levels, etc. In order for water services to be sustainable in this context, economic growth has to be targeted towards equitable distribution of benefits (i.e. the needs of the people) as well as being sensitive to the needs of the environment. The complex nature of urban water systems requires more than just an assessment of specific social and economic criteria as part of a decision support framework; it should also take into account adaptive management and integrated urban water management issues at strategic and operational levels (Pearson et al., 2010) so as to take into account the various interactions that take place across the urban water cycle.

\section{Sustainability index for integrated urban water management}

Various existing indices were investigated with a view to identifying an appropriate methodology and a core set of indicators/ variables to provide input into the SIUWM. An adapted life cycle assessment approach, as used by Lundin and Morrison (2002) for the development of environmental sustainability indicators for urban water systems, was ultimately adopted. This included, inter alia, the following steps: 


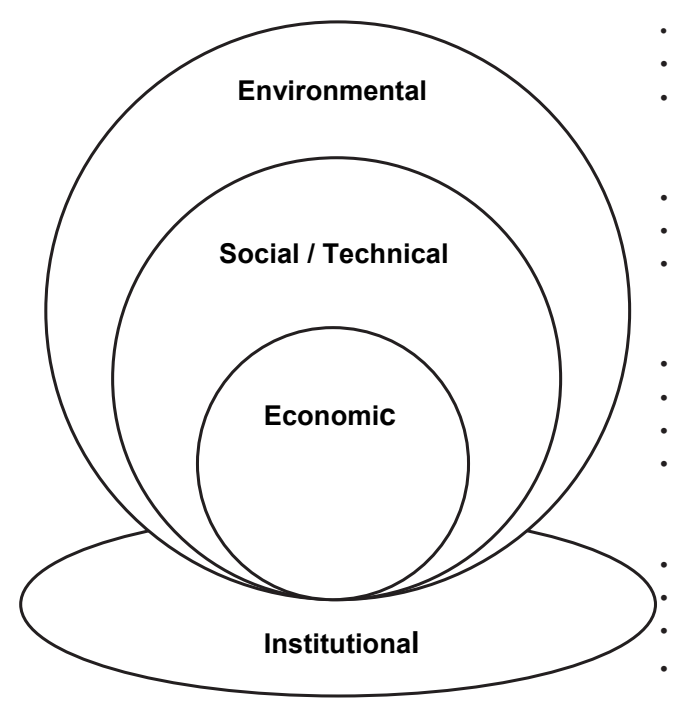

- Surface and groundwater quality stability

- No development in floodplains

- Water conservation strategies linked to pollution and flooding

- Integrated planning / service provision

- Infrastructure integrity

- Total water management

- Operational WATSAN business unit

- Enabling budgetary frameworks

- Ownership/willingness to pay

- Inter-governmental economic arrangements

Good governance; enabling legislation

Guiding documentation on strategy

Partnerships between three spheres of government

- Research collaboration

Figure 1

Vision of sustainability in urban water management in South African cities (adapted from SACN, 2011)

- Developing the theoretical framework

- Selecting indicators and showing links to others

- Identifying data inputs and normalising/ standardising data where necessary

- Applying weights and aggregating indicators

- Computing the index and interpreting/ disseminating results

An important starting point to the selection of indicators is agreement on a (shared) vision of sustainability in the urban water sector; this was established by way of participatory interview processes with stakeholders at several of the larger municipalities in SA. Comparisons with other sustainability assessment efforts, such as that done by the South African Cities Network (SACN) for the State of the Cities reporting, and various other indicator initiatives, were also undertaken to define this vision. The various aspects of the vision were then linked to the four components of sustainability as shown in the systems model (Fig. 1), where the economic and social/ technical systems are embedded within the larger ecosystem, and all integrated through an effective institutional governance system that holds them together within a regulatory framework (SACN, 2011).

Once this had been done, it was possible to start identifying the underlying challenges which had to be represented and measured. A learning cycle approach was adopted for indicator selection (Fig. 2), including an audit of potential data sources, with a specific focus on those which were easily obtainable and regularly updated, i.e. existing SA water services benchmarking and indicator initiatives (e.g. RPMS, Blue Drop, Green Drop).

The final list of 16 indicators and 35 variables used in the SIUWM are shown in Table 1, which also outlines the likely source of data for each variable, as identified by way of the links with other existing assessment initiatives in SA (e.g. RPMS). The indicators/variables require both qualitative and quantitative data over widely differing ranges; standardisation was therefore required to place them within comparable scales. This was achieved by expressing each indicator/variable on a categorical scale from 0 to 5 , where the values were either based on pre-established standards (e.g. WHO guidelines), or determined subjectively, using literature or expert opinion. The development of the SIUWM as an interactive spreadsheetbased program allowed for aggregation into a single figure result, as well as the attribution of different weights to variables. A composite index approach was employed to compute the overall sustainability index score for a particular urban area as the weighted geometric mean of the four component scores. In this approach, the standardised value for each variable is multiplied by its attributed weight (in this case equal weighting was adopted) to give a value on a scale of $0-5$, and the score for each indicator is then determined as the geometric mean of its variable scores. The scores for the four components are determined in a similar manner, and expressed as percentages by dividing by the full score of 5 and multiplying by 100 .

\section{SIUWM CASE STUDY RESULTS}

Table 2 highlights the SIUWM and component scores from the sustainability assessment of the nine case study cities - Buffalo City (BC), Cape Town (CT), Ekurhuleni (EK), eThekwini (ET), Johannesburg (JHB), Mangaung (MN), Msunduzi (MS), Nelson Mandela Metro (NMM) and Tshwane (TS) - using 2010 data from RPMS, StatsSA and other sources. The SIUWM highlights inherent strengths and weaknesses in the management of water services in the cities, and consequently in the performance across each dimension of sustainability, drawing attention to specific challenges through interrogation of the individual indicator and variable results. For example, the comparative scores for the nine cities reveal that the 'Economic' component fares the worst, with an average score of just $43 \%$. An evaluation of the indicator results shows that this is mostly as a result of poor performance in 'Capacity to pay (or access services)' and 'Cost recovery/funding' (Fig. 3). Further scrutiny of the variable scores for the 'Cost recovery' indicator highlights non-revenue water (NRW) as the major challenge facing most WSAs (Fig. 4).

It is clear that urban water systems in South Africa are not homogeneous entities; there are areas of poor performance and also areas of strong performance, and the challenge is to focus on what can be learned from these variations. Whilst substantial progress has been made in addressing historical inequalities in access to water services, there are still significant backlogs, 


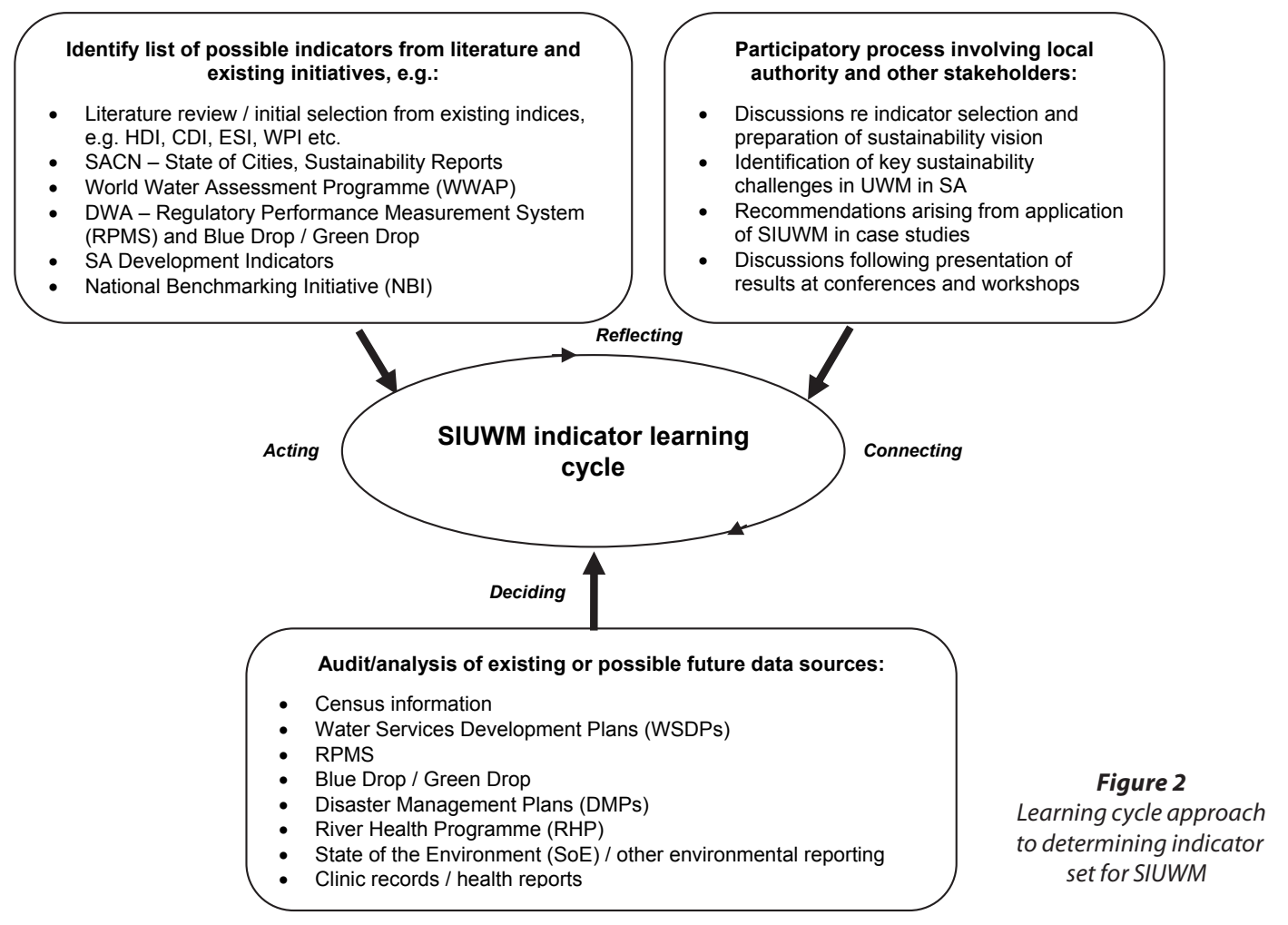

and, perhaps more importantly, real difficulties in sustaining service provision over the long term. This arises from uncertainties about the Government's ability to maintain funding levels in the sector as well as fragmented and problematic institutional capabilities. In many urban areas, water services infrastructure is reaching replacement age, but funding constraints, a lack of lifecycle asset planning, poor design, weak technical skills and poor operating and maintenance practices are hampering the required maintenance and replacement

programmes (RSA, 2011a). The consequences of this include higher long-term costs, increased percentages of NRW (currently estimated to be costing the country over R2 billion per year), pollution and health problems resulting from dysfunctional water and sanitation infrastructure, and increased social tensions. It is also suggested that the governance focus in the water sector has (unsuccessfully) been on 'designing highly sophisticated water management strategies and then attempting to build the capacity to implement them' (Schreiner et al., 2009), highlighting the fact that introducing new and complex governance systems can make capacity challenges all the more difficult, with significant impacts on the sustainability of water services.

\section{CONCLUSIONS}

The main aim of this research was to develop a comprehensive understanding of sustainability in the context of urban water management in a developing country context, in order to determine what the 'leverage points' are in moving towards sustainability. For urban water services to be sustainable in the long term, an accountable government (at both national and local level) is necessary. Robust measures of success and failure in the sector are required to inform the actions required to ensure service delivery, social advancement and economic growth into the future. The Sustainability Index for Integrated Urban Water Management (SIUWM) was developed with a view to linking existing performance measurement processes in the sector with a broader sustainability assessment process so as to provide a more detailed analysis. Sustainability assessment in the urban water sector is not only about taking stock of progress - it is also about identifying shortcomings and challenges so as to contribute to initiatives and policy making aimed at achieving sustainability. In this way the assessment process itself can constitute a key driver of change.

Systems thinking and solution-oriented, integrated planning approaches are key to the sustainability of any water services delivery/management program. For example, there is room for greater integration of the water supply, stormwater and wastewater components of the urban water cycle in Water Services Authorities in SA, but it is in the non-technical areas where the most significant improvements can be made; i.e., information dissemination, skills enhancement, and performance assessment. Sustainable urban water services require a wide range of technologies, actions and behaviours, and solutions can take many forms, tailored to the specific requirements of the urban environment in which they reside.

Benchmarking initiatives are usually service-specific, while the SIUWM aims to be cross-cutting; it not only assesses the technical side of water services, but institutional, environmental and social aspects also. It can be used to highlight key urban water management issues and priorities for action by decisionmakers. The SIUWM is therefore more than a benchmarking initiative - the index is complex enough to take into account different stakeholders' views and thus promote dialogue towards a more integrated urban water management approach. In this way, the methodology used by the SIUWM is very different to the regulatory-inspired benchmarking approaches of systems such as RPMS and Blue Drop / Green Drop, as it aims to give a broad, integrated assessment of the potential for a particular urban water system to be sustainable.

If a tool such as the SIUWM is to be used effectively by municipal engineers to leverage decision-makers and politicians in South Africa, it needs to be simple-to-use and 


\begin{tabular}{|c|c|c|c|}
\hline \multicolumn{4}{|c|}{$\begin{array}{c}\text { TABLE } 1 \\
\text { Data sources for SIUWM variables }\end{array}$} \\
\hline Component & Indicator & Variable & $\begin{array}{l}\text { Data source - published / } \\
\text { unpublished }\end{array}$ \\
\hline \multirow{10}{*}{ Social } & \multirow{4}{*}{ Level of service } & LOS Water supply & Census surveys \\
\hline & & LOS Sanitation & Census surveys \\
\hline & & \begin{tabular}{|l|} 
LOS Solid waste collection \\
\end{tabular} & Census surveys \\
\hline & & LOS Drainage & Interviews \\
\hline & \multirow{2}{*}{ Health } & Under 5 mortality rate & Gaffneys / State of the cities \\
\hline & & HIV/AIDS prevalence & Gaffneys / State of the cities \\
\hline & \multirow{2}{*}{ Vulnerability to disasters } & $\%$ population in informal dwellings & Census / State of the cities \\
\hline & & Risk management / disaster mitigation & DMP / interviews \\
\hline & \multirow{2}{*}{ Education and awareness } & Customer service standards & RPMS - KPI 7 \\
\hline & & Secondary education levels & Gaffneys / State of the Cities \\
\hline \multirow{5}{*}{ Economic } & \multirow{2}{*}{$\begin{array}{l}\text { Capacity to pay or access } \\
\text { services }\end{array}$} & Unemployment rate & Gaffneys / Census surveys \\
\hline & & Levels of inequality (Gini coefficient) & State of the world's cities \\
\hline & \multirow{2}{*}{ Cost recovery } & WSA financial performance & RPMS - KPI 9 \\
\hline & & Water use efficiency / NRW & RPMS - KPI 11 \\
\hline & Asset management & Strategic asset management & RPMS - KPI 10 \\
\hline \multirow{13}{*}{ Environment } & \multirow{3}{*}{$\begin{array}{l}\text { Resource sustainability/ } \\
\text { feasibility (quantity) }\end{array}$} & Per capita water availability & WSDP / SoE / interviews \\
\hline & & Sustainability of source & WSDP / interviews \\
\hline & & $\begin{array}{l}\text { Demand for water resources (average population } \\
\text { growth rate) }\end{array}$ & IDP / State of the Cities / Census \\
\hline & \multirow{3}{*}{$\begin{array}{l}\text { Sustainability of water } \\
\text { resources (quality) }\end{array}$} & Potable water quality (Blue Drop) & RPMS - KPI 5 / Blue Drop \\
\hline & & Water resource quality (River health) & SoE / River Health Programme \\
\hline & & Groundwater quality & SoE / interviews \\
\hline & \multirow{2}{*}{ Climate change response } & Energy consumption by water sector & Interviews \\
\hline & & Climate change strategic planning & Interviews \\
\hline & \multirow{3}{*}{$\begin{array}{l}\text { Use (resource distribu- } \\
\text { tion per sector) }\end{array}$} & Domestic water demand & WSDP / interviews \\
\hline & & Industrial water demand & WSDP / interviews \\
\hline & & Ecosystems water demand & WSDP / interviews \\
\hline & Wastewater management & Wastewater quality (Green Drop) & RPMS - KPI 6 / Green Drop \\
\hline & Stormwater management & WSUD / SuDS policy, implementation & Interviews \\
\hline \multirow{7}{*}{ Institutional } & \multirow{2}{*}{ Governance model } & Defined roles and responsibilities & Interviews \\
\hline & & Departmental integration & Interviews \\
\hline & \multirow{3}{*}{$\begin{array}{l}\text { Progress with meeting } \\
\text { targets (MDGs etc) }\end{array}$} & Access to water supply & RPMS - KPI 1 \\
\hline & & Access to sanitation & RPMS - KPI 2 \\
\hline & & Access to Free Basic Water (FBW) & RPMS - KPI 3 \\
\hline & \multirow{2}{*}{$\begin{array}{l}\text { Institutional capacity/ } \\
\text { policies }\end{array}$} & WDM policy / IUWM approach & WSDP / interviews \\
\hline & & Institutional effectiveness & RPMS - KPI 8 \\
\hline
\end{tabular}

RPMS - Regulatory Performance Measurement System; WSDP - Water Services Development Plan; DMP - Disaster Management Plan; IDP - Integrated Development Plan; SoE - State of Environment report

\begin{tabular}{|c|c|c|c|c|c|c|c|c|c|c|}
\hline \multicolumn{11}{|c|}{$\begin{array}{c}\text { TABLE } 2 \\
\text { SIUWM scores for SACN cities }\end{array}$} \\
\hline \multirow{2}{*}{ SIUWM Component } & \multicolumn{10}{|c|}{ SACN cities } \\
\hline & $\mathrm{BC}$ & CT & EK & ET & $\mathrm{JHB}$ & $\mathrm{MN}$ & MS & NMM & TS & Ave \\
\hline Social & $57 \%$ & $69 \%$ & $58 \%$ & $60 \%$ & $63 \%$ & $58 \%$ & $65 \%$ & $61 \%$ & $53 \%$ & $60 \%$ \\
\hline Economic & $35 \%$ & $62 \%$ & $43 \%$ & $42 \%$ & $42 \%$ & $41 \%$ & $38 \%$ & $46 \%$ & $44 \%$ & $43 \%$ \\
\hline Environmental & $58 \%$ & $64 \%$ & $55 \%$ & $55 \%$ & $64 \%$ & $40 \%$ & $52 \%$ & $61 \%$ & $59 \%$ & $57 \%$ \\
\hline Institutional & $57 \%$ & $66 \%$ & $67 \%$ & $77 \%$ & $54 \%$ & $68 \%$ & $63 \%$ & $72 \%$ & $56 \%$ & $64 \%$ \\
\hline Overall SIUWM score & $51 \%$ & $65 \%$ & $55 \%$ & $57 \%$ & $55 \%$ & $50 \%$ & $53 \%$ & $59 \%$ & $53 \%$ & $55 \%$ \\
\hline
\end{tabular}

transparent; it must be reproducible; and it must not be overly dependent on personal input and stakeholder participation. For a multi-dimensional sustainability assessment such as this to become a real asset, it needs to be regularly (at least annually) recalculated and presented as a time-series. Only in this way can an analysis of trends towards sustainability in urban water management in SA be established. Poor quality data can limit the usefulness of such a process and it is therefore crucial to obtain data from trusted sources. Effective development of time-series data requires that the data remains comparable 


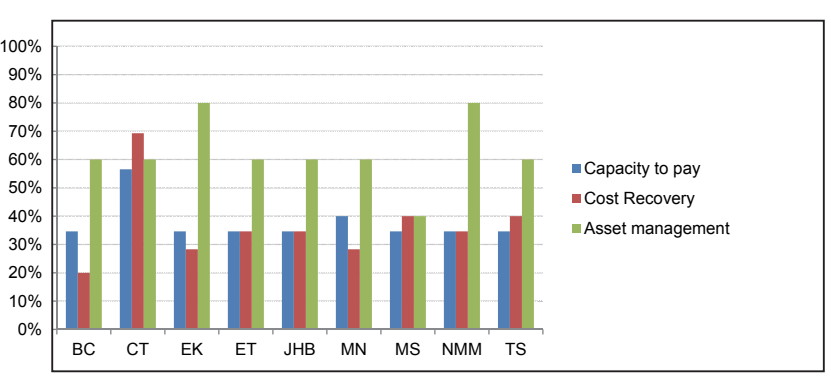

Figure 3

Economic component - indicator scores for SACN cities

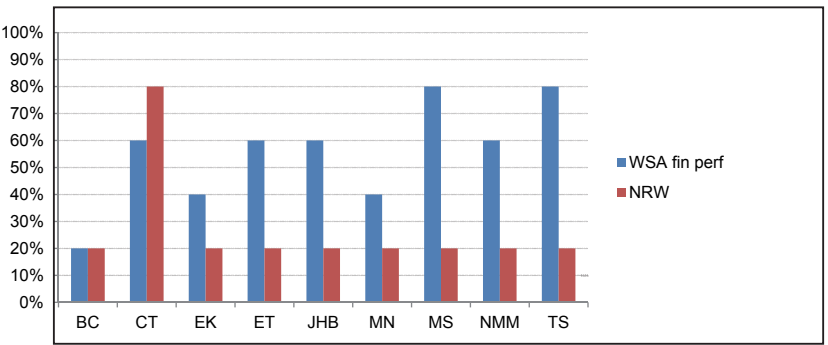

Figure 4

Cost recovery indicator - variable scores for SACN cities. (WSA fin perf - Water Services Authority's financial performance; NRW - non-revenue water)

over time through the use of standardised data sets, as well as frequent data updating (Van den Berg and Danilenko, 2011). It was for this reason that the decision was taken to make use of existing urban water management performance measurement systems to provide input to the SIUWM.

As was pointed out in the Introduction, developing a fact-based vision for the urban water sector is a critical first step to making a water sector transformation reform agenda possible (Addams et al., 2009). Linking such a vision to action requires high-level energy and support, as well as commitment from decision-makers at local and national level, particularly in respect of the ongoing collection and management of the data required to inform such an exercise. Once this has been achieved, policy makers, the private sector and civil society need to work together to put the transformation towards sustainability into practice. In the words of Tàbara et al. (2008): '...we do not need new tools, we already have many. What we need is to apply the ones we already have and take the most advantage of their potentialities'.

\section{ACKNOWLEDGEMENTS}

The research was supported by the South African National Research Foundation (NRF).

\section{REFERENCES}

ADDAMS L, BOCCALETTI G, KERLIN M and STUCHTEY M (2009) Charting Our Water Future - Economic frameworks to inform decision-making. 2030 Water Resources Group. URL: http://www. mckinsey.com/App_Media/Reports/Water/Charting_Our_Water Future Full Report 001.pdf (Accessed September 2011).

BECK M, DAVIS C, KENWAY S, PORRO J, MATSUI S, CRAWFORD G, HILGER H and ZHANG H (2012) Sustainability in the water sector. In LI H (ed.) Global trends and challenges in water science, research and management. A compendium of hot topics and features from IWA specialist groups. International Water Association (IWA), London, England. ISBN 9781780401065.

BROWN R, KEATH N and WONG T (2008) Transitioning to Water Sensitive Cities: Historical, Current and Future Transition States. Proc. $11^{\text {th }}$ International Conference on Urban Drainage, Edinburgh, Scotland. 10 pp. ISBN 978-1-89979-621-2.

DWA (DEPARTMENT OF WATER AFFAIRS, SOUTH AFRICA) (2010) National Water Services Regulation Strategy - January 2010. Department of Water Affairs, Pretoria, South Africa.

DWAF (DEPARTMENT OF WATER AFFAIRS AND FORESTRY, SOUTH AFRICA) (2008) Fact sheets for water sector. Directorate: Water Service Sector Development, Pretoria, South Africa.

LUNDIN M and MORRISON G (2002) A life cycle assessment based procedure for development of environmental sustainability indicators for urban water systems. Urban Water 4 145-152.

MITCHELL V (2006) Applying Integrated Urban Water Management concepts: A review of Australian experience. Environ. Manag. 37 (5) 589-605.

PEARSON L, COGGAN A, PROCTOR A and SMITH T (2010) A sustainable decision support framework for urban water management. Water Res. Manag. 24 (2) 363-376.

RSA (REPUBLIC OF SOUTH AFRICA) (1998) National Water Act, Act No. 36 of 1998. Government Printer, Pretoria, South Africa.

RSA (REPUBLIC OF SOUTH AFRICA) (2011a) Diagnostic Report. National Planning Commission, The Presidency, Pretoria, South Africa.

RSA (REPUBLIC OF SOUTH AFRICA) (2011b) National Development Plan. Vision for 2030. The Presidency: National Planning Commission, Pretoria, South Africa. ISBN: 9780621404753.

SACN (SOUTH AFRICAN CITIES NETWORK) (2011) State of the Cities Report 2011. Towards resilient cities: A reflection on the first decade of a democratic and transformed local government in South Africa 2001-2010. SACN, Johannesburg, South Africa.

SCHREINER B, PEGRAM G and VON DER HEYDEN C (2009) Reality check on water resources management: Are we doing the right things in the best possible way? Development Planning Division Working Paper Series No. 11. Development Bank of Southern Africa, DBSA.

TÀBARA A, ROCA E and MADRID C (2008) Integrated sustainability assessment of water systems: lessons from the Ebro River Basin. Int. J. Innovation Sustainable Dev. 3 (1/2) 48-69.

TISSINGTON K, DETTMANN M, LANGFORD M, DUGARD J and CONTEH S (2008) Water services fault lines - An assessment of South Africa's water and sanitation provision across 15 municipalities. Centre for Applied Legal Studies (CALS), University of the Witwatersrand, Johannesburg, South Africa. ISBN 978-0-620-42880-4.

UNDP (UNITED NATIONS DEVELOPMENT PROGRAMME) (2011) Human Development Report 2011. Sustainability and equity: A better future for all. Palgrave Macmillan, New York. ISBN: 978-0-230-36331-1.

UNESCO-IHP (UNITED NATIONS EDUCATIONAL, SCIENTIFIC AND CULTURAL ORGANISATION - INTERNATIONAL HYDROLOGICAL PROGRAMME) (2008) IHP-VII Water dependencies: Systems under stress and societal responses [2008-2013]. UNESCO-IHP, Paris, France.

UNESCO-IHE (UNITED NATIONS EDUCATIONAL, SCIENTIFIC AND CULTURAL ORGANISATION - INSTITUTE FOR WATER EDUCATION) (2009) PROBE Full Proposal - Benchmarking for pro-poor water services provision, Version 8. Global Partnership for Water Education and Research (POWER), UNESCO-IHE, Delft, The Netherlands.

UNW-DPAC (UN-WATER DECADE PROGRAMME ON ADVOCACY AND COMMUNICATION) (2010) Water and cities: Facts and figures. URL: http://www.un.org/waterforlifedecade/ swm cities zaragoza 2010/pdf/facts and figures long final eng.pdf (Accessed November 2011).

VAN DEN BERG C and DANILENKO A (2011) The IBNET Water Supply and Sanitation Performance Blue Book. The International Benchmarking Network for Water and Sanitation Utilities Databook. The World Bank, Washington DC. ISBN 978-0-8213-8582-1. 